\title{
BADMINTON: AMPLIANDO A CULTURA ESPORTIVA DAS ESCOLAS PÚBLICAS DE PARNAMIRIM
}

\section{RESUMO}

O trabalho em tela trata-se de uma ação extensionista que visa atender à comunidade escolar circunvizinha ao Campus do IFRN em Parnamirim, surgindo como fruto das parcerias entre o IFRN, Secretaria Estadual de Educação (2a DIRED) e a Federação Norteriograndense de Badminton (FNBd). Nesse sentido, possui três frentes de atuação: 1) Divulgação do Badminton nas escolas por meio de oficinas com os estudantes, 2) Capacitação de professores da rede por meio de minicursos e 3) Oferta de aulas esportivas para crianças em horários alternativos. Tem ainda como principais objetivos: Difundir a prática do Badminton nas escolas públicas de Parnamirim; Divulgar e promover as ações do IFRN junto à comunidade local visando estimular os beneficiados a ingressarem em cursos regulares da nossa Instituição. O projeto encontra-se em desenvolvimento e pode-se elencar algumas ações realizadas como reuniões com as entidades participantes, oficinas nas escolas e o agendamento de minicursos.

Palavras-chave: Badminton. Cultura Esportiva. Escolas Públicas.

\section{INTRODUÇÃO}

O Brasil é considerado, nos cenários nacional e internacional, como "o país do futebol". Essa afirmação ocorre em virtude do contexto histórico, político e social que foi construído em torno dessa manifestação esportiva. No entanto, o Brasil também pode tornar-se o país de outros esportes, desde que a população brasileira tenha o acesso a outras opções para além do hegemônico futebol. Nesse sentido, o Ministério do Esporte tem buscado tornar o Brasil uma potência olímpica por meio de programas e ações (Lei de Incentivo ao Esporte, Programa Segundo Tempo, Bolsa-Atleta, Esporte e lazer da cidade, dentre outras),

No entanto, essas ações não têm chegado de forma sistemática ao nosso estado nem tão pouco às escolas públicas de Parnamirim. Assim, motivados por essa realidade, realizamos uma 
rodada de conversas, com o setor de Educação Física e Esportes da 2a DIRED/RN com o intuito de identificarmos o interesse de uma parceria com o IFRN (Campus Parnamirim) com relação ao nosso projeto. Nesse sentido, a 2a DIRED manifestou pleno interesse em firmar a parceria no sentido de levar o Badminton, enquanto conhecimento, para os alunos nas aulas de Educação Física, como também, possibilitar a formação de professores para atuarem nas escolas.

Outro fator que tem viabilizado o nosso trabalho tem sido a participação efetiva da Federação Norteriograndense de Badminton (FNBd), pois a mesma vem oferecendo apoio operacional, como o empréstimo de materiais necessários ao desenvolvimento da modalidade. Além disso, o coordenador desta ação vem sendo capacitado em diversos cursos nacionais e internacionais na área de Badminton ofertados pela Confederação Brasileira de Badminton (CBBd) e a Federação Mundial de Badminton (BWF).

Nesse sentido, a nossa ação foi concebida a partir dos objetivos: difundir a prática do Badminton nas escolas públicas de Parnamirim; capacitar professores para atuarem com o ensino do Badminton na escola por meio de minicursos; estimular a prática esportiva como possibilidade de lazer e opção para a melhoria da qualidade de vida; contribuir para a melhoria das relações interpessoais dos beneficiados; promover a convivência social, o aumento da autoestima e dos valores éticos e de cidadania; democratizar - acesso à prática de atividades esportivas devidamente orientadas; divulgar, apresentar e promover as ações do IFRN junto à comunidade local visando estimular os beneficiados a ingressarem futuramente nos cursos regulares do campus.

Para atendermos tais objetivos estruturamos a nossa metodologia de ação a partir de 8 etapas distintas, a saber: 1ạ- Divulgação de edital de seleção de bolsistas e realização de processo seletivo; 2a - Reuniões para apresentação do projeto; 3a - Realização das oficinas nas escolas; 4a - Realização de minicursos para professores; 5 a Divulgação e inscrições; 6 a - Execução das aulas; 7a - Coleta de dados; 8 - Culminância e avaliação do projeto.

\section{QUE ESPORTE É ESSE?}

O Badminton teve suas origens por volta de 1600 e deriva de um jogo chamado Battledore and Shuttlecock, em que o objetivo era bater com uma raquete em uma peteca o maior número de vezes possível, sem deixá-la cair. Em meados de 1800 , soldados ingleses que estavam na Índia desenvolveram uma versão do jogo denominada "Poona", e levaram a modalidade para seu país. A modalidade foi apresentada em 1870 para a realeza local pelo Duque de Beaufort, em seu palácio chamado Badminton House, na Inglaterra, daí o nome que rebatizou o esporte (GONÇALVES, 2012).

Nasceu no Brasil como esporte de competição em meados dos anos 80 , por meio de imigrantes chineses, belgas, ingleses, dentre outros, que praticavam o esporte em clubes e associações no estado de São Paulo (FONSECA; SILVA, 2012) e foi trazido para o Rio Grande do Norte pelo professor Antônio Carlos (Cazuza), no ano de 2006 por meio de pesquisas e da compra de materiais da modalidade na internet.

O Badminton é um esporte de raquete com peteca que lembra o voleibol e o tênis de campo, no entanto contém regras que o atribuem características singulares, como as dimensões da quadra $(16,40 \mathrm{~m}$ por $6,10 \mathrm{~m})$ e as suas formas de disputa: simples, duplas e duplas mistas. Seu objetivo principal consiste na ação de colocar a peteca no solo da quadra do adversário, fazendo-a passar por cima da rede e, evitando que o adversário faça o mesmo. Sua realização ocorre preferencialmente em ginásios esportivos em que a ausência do vento é um aspecto fundamental para as competições oficiais, todavia esse fator não impede a sua realização de maneira amadora em pátios, praças, escolas dentre outros espaços abertos com a presença de vento.

Embora ainda seja pouco difundido em nosso país ele é considerado como um dos esportes mais populares do mundo, principalmente nos países da Europa e Ásia; tais como Inglaterra, Suécia, Dinamarca, Indonésia e China. Além disso, é conhecido como o esporte de raquete mais veloz do mundo, em que a peteca pode atingir em nível profissional a velocidade de $400 \mathrm{Km} / \mathrm{h}$.

\section{PROJETO EM AÇÃo}

O nosso projeto inaugurou as suas ações em janeiro de 2014 e obteve os seus ajustes finais em fevereiro, durante reunião realizada na 2a DIRED com os técnicos da 2a DIRED (figura 1). No mês seguinte o projeto foi divulgado em uma reunião ampliada com gestores e professores de Educação Física das escolas estaduais na Câmara Municipal de Parnamirim (Figura 2). 


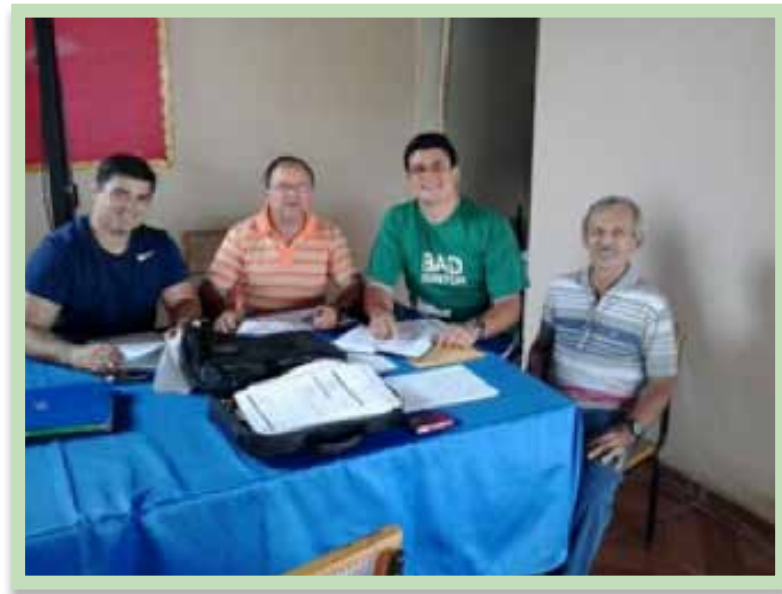

Figura 1 - Reunião na 2a DIRED - Parnamirim

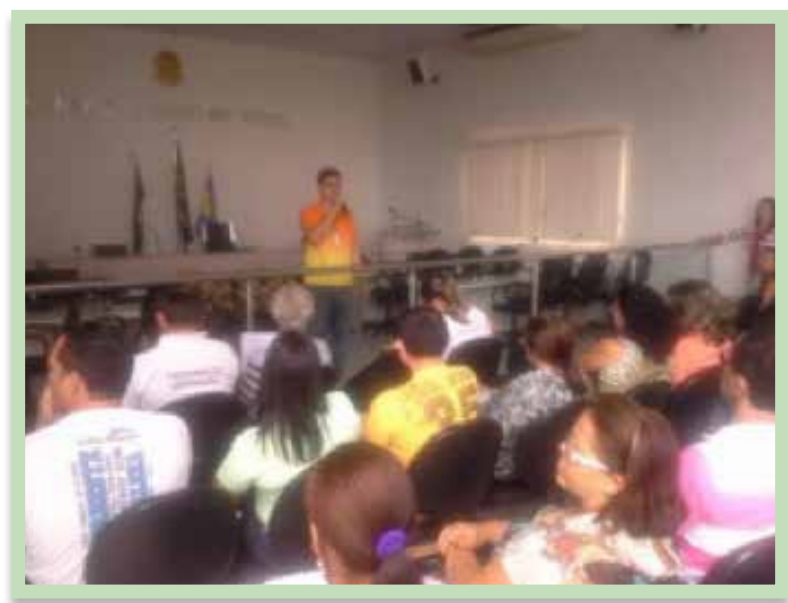

Figura 2- Divulgação do projeto em reunião ampliada.

A ideia foi bem acolhida pelos gestores e professores de Educação Física participantes do encontro. Dessa forma, iniciamos o agendamento e a realização das oficinas nas escolas. Para tanto, estabelecemos como meta a realização de oficinas em pelo menos 10 escolas, num período que vai até o fim de agosto de 2014.

Nesse sentido, atingimos até o momento quatro escolas: Manoel Germano dos Santos, Roberto Rodrigues Krause, Santos Dumont e Escola Maria de Jesus. Além disso, agendamos para o mês de agosto a realização de dois minicursos, sendo o primeiro com professores de Educação Física da 2a DIRED e o segundo com os professores de Educação Física do IFRN. Esperamos iniciar, na primeira semana de setembro, aulas de Badminton com os alunos encaminhados pelas escolas parceiras do projeto. A culminância da nossa ação será a "I Copa IFRN de Badminton" e reunirá beneficiados, professores das escolas parceiras, representantes da 2a DIRED, FNBd e IFRN para juntos celebrarmos a ação desenvolvida. As figuras 3 e 4 mostram momentos das oficinas em outras escolas.
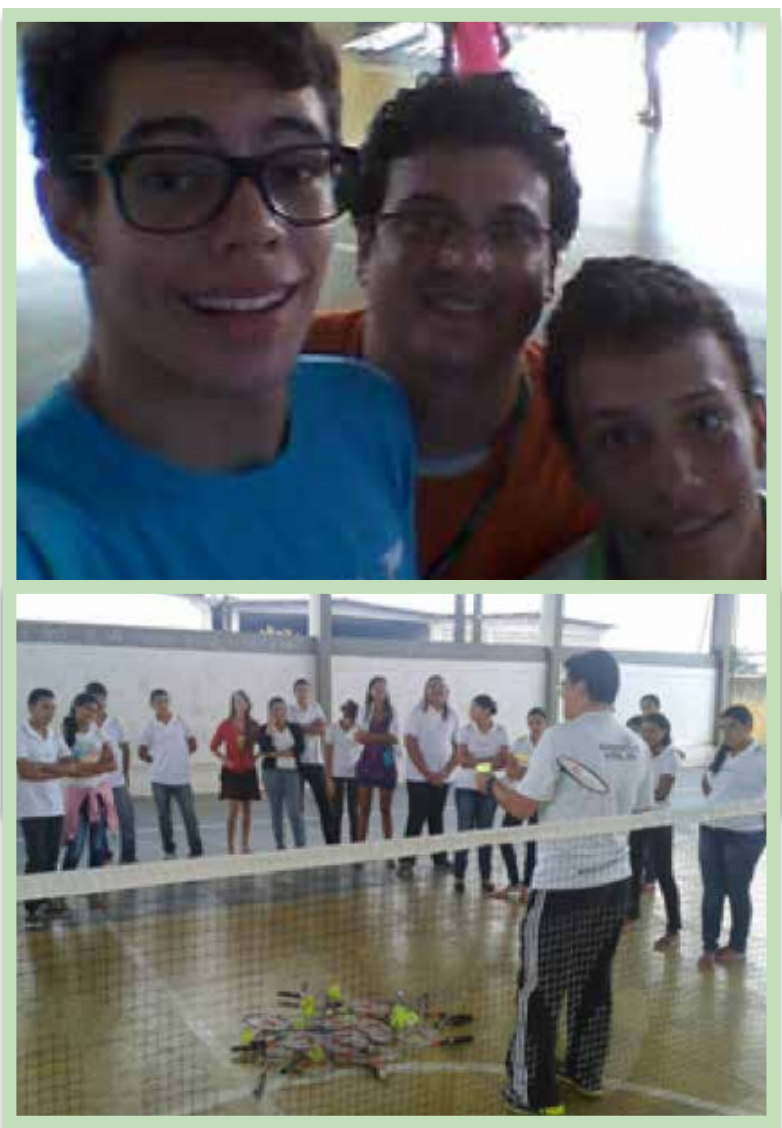

Figura 4 - Momentos iniciais na escola Krause.

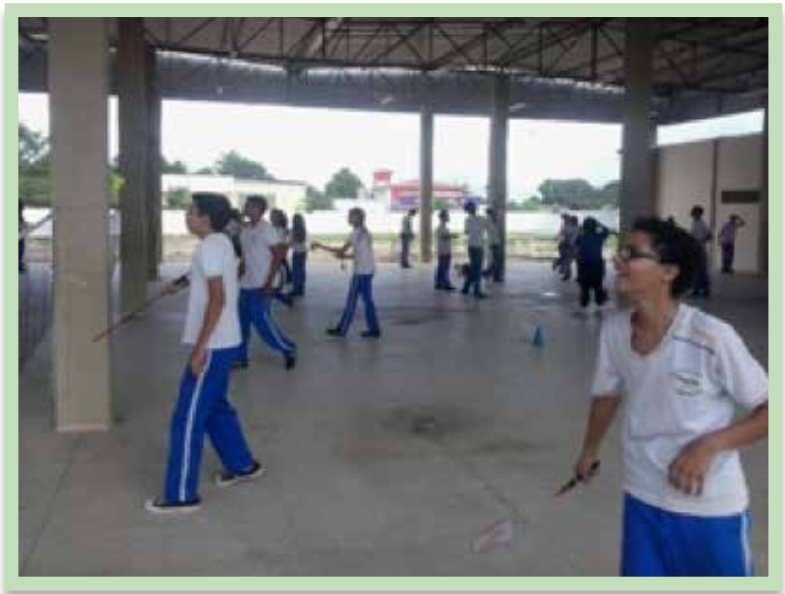

Figura 5 - Oficina no pátio da escola Santos Dumont

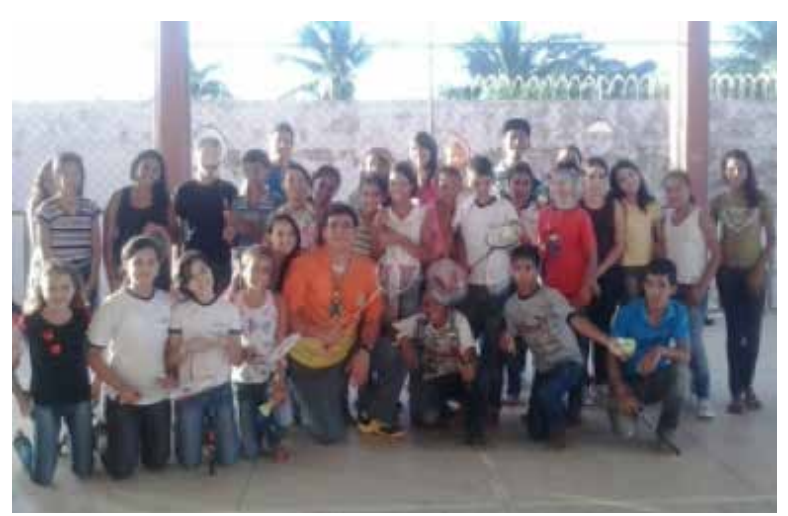

Figura 6 - Oficina na escola Maria de Jesus 


\section{CONCLUSÃO}

Levar o Badminton às escolas tem sido uma experiência gratificante, pois a dinâmica do esporte é lúdica e atrativa, além de ser uma excelente opção de atividade física e lazer. Temos consciência que estamos proporcionando aos estudantes a ampliação de sua cultura esportiva, oferecendo-lhes a oportunidade de vivenciarem um esporte pouco difundido em nosso estado, além de capacitarmos professores para atuarem na área. Dessa forma, não poderíamos deixar de agradecer ao IFRN por estar fomentando o desenvolvimento de ações que transponham os seus muros.

\section{REFERENCIAS}

FONSECA, Keiko Verônica Ono; SILVA, Paulo Roberto Bastianini da. Badminton: manual de fundamentos e exercícios. Curitiba: M. M. Ono, 2012.

GONÇALVES, Ricardo. 0 jogo Badminton. Arapongas: SESI-PR, 2012. 